\title{
Comparative Pharmacokinetics of Cefquinome (Cobactan 2.5\%) following Repeated Intramuscular Administrations in Sheep and Goats
}

\author{
Mohamed El-Hewaity, ${ }^{1}$ Amera Abd El Latif, ${ }^{1}$ Ahmed Soliman, ${ }^{2}$ and Mohamed Aboubakr ${ }^{3}$ \\ ${ }^{1}$ Department of Pharmacology, Faculty of Veterinary Medicine, University of El-Sadat City, Minoufiya 32897, Egypt \\ ${ }^{2}$ Department of Pharmacology, Faculty of Veterinary Medicine, Cairo University, Giza 12211, Egypt \\ ${ }^{3}$ Department of Pharmacology, Faculty of Veterinary Medicine, Benha University, Moshtohor, Toukh, Qalyubia 13736, Egypt
}

Correspondence should be addressed to Mohamed El-Hewaity; melhewaty@yahoo.com

Received 28 December 2013; Revised 13 April 2014; Accepted 27 April 2014; Published 19 May 2014

Academic Editor: Nora Mestorino

Copyright (C) 2014 Mohamed El-Hewaity et al. This is an open access article distributed under the Creative Commons Attribution License, which permits unrestricted use, distribution, and reproduction in any medium, provided the original work is properly cited.

\begin{abstract}
The comparative pharmacokinetic profile of cefquinome was studied in sheep and goats following repeated intramuscular (IM) administrations of $2 \mathrm{mg} / \mathrm{kg}$ body weight. Cefquinome concentrations in serum were determined by microbiological assay technique using Micrococcus luteus (ATCC 9341) as test organism. Following intramuscular injection of cefquinome in sheep and goats, the disposition curves were best described by two-compartment open model in both sheep and goats. The pharmacokinetics of cefquinome did not differ significantly between sheep and goats; similar intramuscular dose rate of cefquinome should therefore be applicable to both species. On comparing the data of serum levels of repeated intramuscular injections with first intramuscular injection, it was revealed that repeated intramuscular injections of cefquinome have cumulative effect in both species sheep and goats. The in vitro serum protein-binding tendency was $15.65 \%$ in sheep and $14.42 \%$ in goats. The serum concentrations of cefquinome along $24 \mathrm{~h}$ after injection in this study were exceeding the MICs of different susceptible microorganisms responsible for serious disease problems. These findings indicate successful use of cefquinome in sheep and goats.
\end{abstract}

\section{Introduction}

Cephalosporins are described as $\beta$-lactam antibiotics, based on their common structural feature, containing the $\beta$-lactam ring. A major advantage of the $\beta$-lactam antibiotics is high degree of safety in the target animal [1]. Cefquinome, an aminothiazolyl cephalosporin, is a member of the fourthgeneration of cephalosporins that has been used for veterinary use only [2]. It has broad-spectrum antibacterial activity against clinically important bacteria such as streptococcus spp, staphylococcus spp, pseudomonas spp, E. coli, and grampositive anaerobes $[3,4]$. It has been approved for the treatment of respiratory diseases, acute mastitis, and foot rot in cattle $[5,6]$. The objective of the current study is to determine whether there are differences between sheep and goat in the disposition of cefquinome following repeated intramuscular administrations of $2 \mathrm{mg} / \mathrm{kg}$ b.wt. once daily for three consecutive days in sheep and goat, to determine if the drug has a cumulative effect after repeated intramuscular administrations and to recommend appropriate dose regimen for cefquinome in sheep and goat.

\section{Materials and Methods}

2.1. Antimicrobial Agent. Cefquinome was obtained from Intervet International Company, Cairo, Egypt, under a trade name: Cobactan 2.5\%.

2.2. Animals. Five healthy nonlactating female Egyptian Baladi sheep (weighing 29-37 kg b.wt.) and five healthy nonlactating female Egyptian Baladi goats (weighing 22$28 \mathrm{~kg}$ b.wt.) were used. Animals were housed in hygienic stable, fed on barseem, Drawa and Concentrate. Water was 
provided ad-libitum. None of the animals were treated with antibiotics for one month prior to the trial. The experiment was performed in accordance with the guidelines set by the Ethical Committee of El-Sadat city University, Egypt.

2.2.1. Experimental Design. Each animal of sheep and goats was injected intramuscularly with $2 \mathrm{mg} / \mathrm{kg}$ b.wt. cefquinome (Cobactan 2.5\%) into the deep gluteal muscle of hindquarter [7] once daily for three consecutive days. Following repeated intramuscular injections in sheep and goats, three milliliters of blood were collected from the jugular vein at 5,15 , and 30 minutes, $1,2,4,8,12$, and $24 \mathrm{~h}$ after each injection. Blood samples were left to clot for 1 hour at room temperature; the clear sera were separated by centrifugation at 3000 r.p.m for 15 minutes and stored at $-20^{\circ} \mathrm{C}$ until assayed.

2.2.2. Drug Bioassay. Concentrations of cefquinome in serum samples were determined by the microbiological assay method described by Arret et al. [8] using Micrococcus luteus (ATCC 9341) as test organism [9]. This method estimated the level of drug having antibacterial activity, without differentiating between the parent drug and its active metabolites. The application of microbiological assay for measuring cefquinome concentration is suitable [9]. Six wells were made at equal distances in standard Petri dishes containing $25 \mathrm{~mL}$ seeded agar. The wells were filled with $100 \mu \mathrm{L}$ of either the test samples or the cefquinome standard concentrations. The plates were kept at room temperature for $2 \mathrm{~h}$ before being incubated at $37^{\circ} \mathrm{C}$ for $18 \mathrm{~h}$. Zones of inhibition were measured using micrometers, and the cefquinome concentrations in the test samples were calculated from the standard curve. Cefquinome (Cobactan 2.5\%) standard solution of concentrations from 0.098 to $25 \mu \mathrm{g} / \mathrm{mL}$ was prepared in antibiotic-free sheep and goat serum and phosphate buffer saline. Standard curves of cefquinome were prepared in antibacterial-free goat serum by the appropriate serial dilution. The standard curve in sheep and goat serum was linear over the range from 0.098 to $25 \mu \mathrm{g} / \mathrm{mL}$ and the value of correlation coefficient $(r)$ was 0.991 . The limit of quantification was $0.098 \mu \mathrm{g} / \mathrm{mL}$. Protein binding of cefquinome (Cobactan 2.5\%) was estimated according to Craig and Suh [10].

2.3. Pharmacokinetic Analysis. A pharmacokinetic computer program (R-strip, Micro-math, Scientific software, USA) was used to determine the least squares best-fit curve for cefquinome concentration versus time data. Following I.M administrations, the appropriate pharmacokinetic model was determined by visual examination of individual concentration-time curves and by application of Akaike's information criterion (AIC) [11]. This program also calculated noncompartmental parameters using the statistical moment theory [12]. The pharmacokinetic parameters were reported as mean \pm SE. Mean pharmacokinetic parameters after repeated IM administrations were statistically compared in sheep and goats using Student's $t$-test [13].

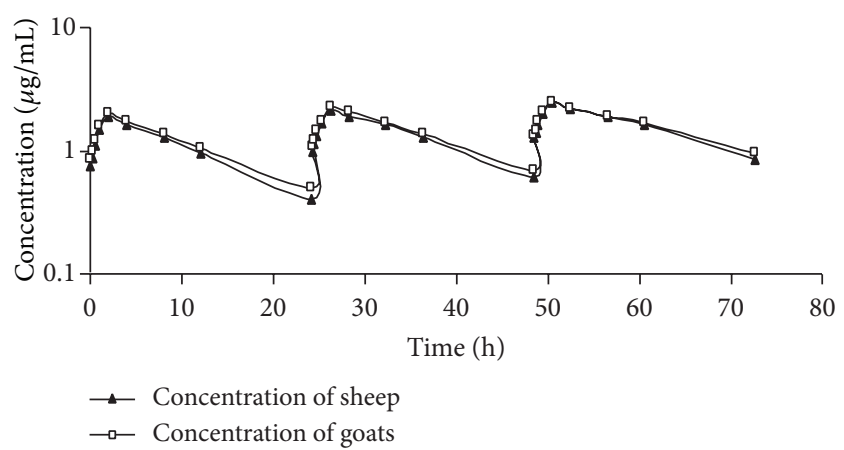

FIgURE 1: Semilogarithmic graph depicting the time-concentration of cefquinome in serum of sheep and goats after repeated intramuscular injections of $2 \mathrm{mg} / \mathrm{kg}$ b.wt. once daily for three consecutive days.

\section{Results}

No clinical signs of adverse effects or intolerance were observed to cefquinome IM injection in sheep and goats. The mean serum concentrations of cefquinome in sheep and goat receiving repeated IM injections of $2 \mathrm{mg} / \mathrm{kg}$ b.wt. once daily for three consecutive days versus time are summarized in Figure 1. These data are best fitted to a two-compartment open model. The results illustrated nonsignificant increase in the serum level of cefquinome in goats compared to values recorded in sheep. Also the results showed a significant increase in serum concentrations of cefquinome after repeated doses compared to the first dose in both species sheep and goat. Cefquinome could be detected in a therapeutic concentration for $24 \mathrm{~h}$ post IM injection in sheep and goats. The pharmacokinetic parameters of cefquinome following repeated IM injections of $2 \mathrm{mg} / \mathrm{kg}$ b.wt. once daily for three consecutive days in sheep and goats are presented in Table 1. There were no significant differences between the pharmacokinetic parameters of cefquinome in sheep and goats after repeated IM doses. The result of in vitro protein binding study indicated that $15.65 \%$ and $14.42 \%$ of cefquinome were bound to sheep and goats serum protein, respectively.

\section{Discussion}

The disposition of cefquinome following intramuscular administration in sheep and goat was best described by a two-compartment open model which was similar to that described in sheep [7,14], piglets [15], and ducks [16]. However, a monocompartment open model was shown to provide the best fit for intramuscular cefquinome plasma concentration-time data in goat [17] and camels [18].

Following first intramuscular injection of cefquinome, the mean peak serum concentrations $\left(C_{\max }\right)$ were $1.80 \pm 0.09$ and $1.88 \pm 0.10 \mu \mathrm{g} / \mathrm{mL}$ in sheep and goats, respectively. These concentrations were achieved at times $\left(T_{\max }\right) 2.61 \pm 0.11$ and $2.62 \pm 0.09 \mathrm{~h}$ in sheep and goats, respectively. These results indicate the slow absorption of this formula. These results differ from those recorded in sheep $\left(C_{\max }\right) 2.60 \pm 0.14 \mu \mathrm{g} / \mathrm{mL}$ 
TABLE 1: Mean ( \pm SE) kinetic parameters of cefquinome following repeated intramuscular injections of $2 \mathrm{mg} / \mathrm{kg}$ b.wt. once daily for three consecutive days in sheep and goats.

\begin{tabular}{|c|c|c|c|c|c|c|c|}
\hline \multirow{2}{*}{ Parameter } & \multirow{2}{*}{ Unit } & \multicolumn{3}{|c|}{ Sheep } & \multicolumn{3}{|c|}{ Goat } \\
\hline & & 1st day & 2nd day & 3rd day & 1st day & 2nd day & 3rd day \\
\hline$A$ & $\mu \mathrm{g} \cdot \mathrm{mL}^{-1}$ & $1.75 \pm 0.10$ & $1.72 \pm 0.06$ & $1.70 \pm 0.12$ & $1.73 \pm 0.08$ & $1.75 \pm 0.09$ & $1.56 \pm 0.13$ \\
\hline$K_{\mathrm{ab}}$ & $\mathrm{h}^{-1}$ & $0.91 \pm 0.036$ & $0.85 \pm 0.06$ & $0.97 \pm 0.02$ & $0.93 \pm 0.015$ & $0.83 \pm 0.035$ & $1.03 \pm 0.02$ \\
\hline$T_{0.5(\mathrm{ab})}$ & $\mathrm{h}$ & $0.76 \pm 0.036$ & $0.82 \pm 0.02$ & $0.73 \pm 0.02$ & $0.73 \pm 0.016$ & $0.82 \pm 0.03$ & $0.67 \pm 0.02$ \\
\hline$B$ & $\mu \mathrm{g} \cdot \mathrm{mL}^{-1}$ & $2.37 \pm 0.14$ & $2.58 \pm 0.10$ & $2.82 \pm 0.21$ & $2.43 \pm 0.09$ & $2.71 \pm 0.08$ & $2.74 \pm 0.13$ \\
\hline$K_{\mathrm{el}}$ & $\mathrm{h}^{-1}$ & $0.074 \pm 0.002$ & $0.057 \pm 0.004$ & $0.05 \pm 0.005$ & $0.068 \pm 0.003$ & $0.057 \pm 0.002$ & $0.044 \pm 0.002$ \\
\hline$T_{0.5(\mathrm{el})}$ & $\mathrm{h}$ & $9.03 \pm 0.89$ & $11.35 \pm 1.40$ & $14.01 \pm 0.99$ & $10.14 \pm 1.42$ & $11.57 \pm 1.28$ & $15.71 \pm 1.52$ \\
\hline$C_{\max }$ & $\mu \mathrm{g} \cdot \mathrm{mL}^{-1}$ & $1.80 \pm 0.09$ & $2.03 \pm 0.14$ & $2.30 \pm 0.10$ & $1.88 \pm 0.10$ & $2.15 \pm 0.09$ & $2.38 \pm 0.08$ \\
\hline$T_{\max }$ & $\mathrm{h}$ & $2.61 \pm 0.11$ & $2.77 \pm 0.21$ & $2.70 \pm 0.15$ & $2.62 \pm 0.09$ & $2.88 \pm 0.19$ & $2.62 \pm 0.13$ \\
\hline $\mathrm{AUC}_{(0-\text { inf })}$ & $\mu \mathrm{g} \cdot \mathrm{h} \cdot \mathrm{mL}^{-1}$ & $29.96 \pm 1.20$ & $40.61 \pm 3.16$ & $54.98 \pm 4.21$ & $31.11 \pm 1.05$ & $45.22 \pm 2.08$ & $61.20 \pm 3.44$ \\
\hline MRT & $\mathrm{h}$ & $14.23 \pm 1.10$ & $16.98 \pm 1.75$ & $20.60 \pm 1.31$ & $15.16 \pm 1.44$ & $16.97 \pm 0.88$ & $23.06 \pm 2.78$ \\
\hline IBD & $\mathrm{h}$ & $27.91 \pm 3.53$ & - & - & $28.82 \pm 4.88$ & - & - \\
\hline
\end{tabular}

A: zero-time intercept of distribution phase; $K_{\mathrm{ab}}$ : first-order absorption rate constant; $T_{0.5(\mathrm{ab})}$ : absorption half-life; $B$ : zero-time intercept of elimination phase; $K_{\mathrm{el}}$ : first-order elimination rate constant; $T_{0.5(\mathrm{el})}$ : elimination half-life; $C_{\max }$ : maximum serum concentration; $T_{\max }$ : time to peak serum concentration; $\mathrm{AUC}_{(0-\text { inf })}$ : area under serum concentration-time curve; MRT: mean residence time; IBD: interval between doses.

at $\left(T_{\max }\right) 0.50 \mathrm{~h}$ [7] and goats $\left(C_{\max }\right) 4.84 \pm 0.23 \mu \mathrm{g} / \mathrm{mL}$ at $\left(T_{\max }\right) 1.50 \mathrm{~h}$ [17]. Such differences are common and frequently related to interspecies variation, assay methods used, age, breed and health status of the animal, and the formulation of the drug used [19].

The absorption half-life of cefquinome following intramuscular injection in sheep and goats was $0.76 \pm 0.036 \mathrm{~h}$ and $0.73 \pm 0.016 \mathrm{~h}$ which was similar to the $T_{0.5 \mathrm{ab}}$ of $0.664 \mathrm{~h}$ reported in one-year-old sheep [14] and to the $T_{0.5 \mathrm{ab}}$ of $0.64 \mathrm{~h}$ reported in goats [17]. However, a shorter absorption half-life of cefquinome has been reported in ducks $(0.12 \mathrm{~h})$ and chicken $(0.17 \mathrm{~h})$ after intramuscular injection [16-20] indicating longer duration for the drug to reach systemic circulation and slower onset of pharmacological action in sheep and goats.

Cefquinome showed long elimination half-life $\left(T_{0.5 \mathrm{el}}\right)$ after intramuscular injection in sheep and goats $9.03 \pm 0.89 \mathrm{~h}$ and $10.14 \pm 1.42 \mathrm{~h}$, respectively; prolonged elimination halflife has been reported for cefquinome in buffalo calves, cattle calves, cows, and goats $12.86,13.46,7.10$, and $8.68 \mathrm{~h}$, respectively [21]. However, a shorter elimination half-life has been reported in sheep $(2.41 \mathrm{~h})$ and goats $(5.86 \mathrm{~h})$ after intramuscular injection [14-17]. Such differences are common and frequently related to interspecies variation, assay methods used, and the formulation of the drug used [19].

The mean residence time (MRT) of cefquinome was $14.23 \pm 1.10 \mathrm{~h}$ in sheep and $15.16 \pm 1.44 \mathrm{~h}$ in goats which was consistent with value recorded in camels $16.74 \mathrm{~h} \mathrm{[18].} \mathrm{The}$ longer $T_{0.5 \mathrm{el}}$ and MRT of cefquinome in the present study indicated long persistence of the drug.

There were no significant differences between the pharmacokinetic parameters of cefquinome in sheep and goats after repeated intramuscular doses. The results were similar to data recorded by Craigmill et al. [22] who found that no significant differences between the pharmacokinetic parameters following intravenous administration of amoxicillin in sheep and goats. Also the results were consistent with those reported by Elsheikh et al. [23] who found that the pharmacokinetics of enrofloxacin did not differ significantly between sheep and goats following intravenous and intramuscular administration.

The relative higher serum concentrations of cefquinome after repeated doses compared to the first dose indicated the accumulation of cefquinome in blood during multiple doses at 24 hours intervals for three consecutive days in sheep and goats. These observations agreed with data reported by ElBanna and Abo El-Sooud [24] who found that progressive daily increase in the mean serum concentrations following the repeated intramuscular injection of ciprofloxacin in lactating goats in a daily dose of $5 \mathrm{mg} / \mathrm{kg} \mathrm{b.wt}$. for five consecutive days.

In vitro protein binding percent of cefquinome in sheep and goat serum was $15.65 \%$ and $14.42 \%$, respectively, so it could be considered as slightly serum protein binding [25].These results were similar to those recorded in sheep $13.002 \%$ [14].

The in vitro efficacy of cefquinome against a wide range of Gram-negative and Gram-positive bacterial pathogens has been demonstrated by various workers. Considering the reported $\mathrm{MIC}_{90 \mathrm{~s}}(0.06-0.39 \mu \mathrm{g} / \mathrm{mL})$ for Escherichia coli, Pasteurella multocida, and Streptococcus agalactiae [2631]. In this discussion an average $\mathrm{MIC}_{90}$ of $0.125 \mu \mathrm{g} / \mathrm{mL}$ of cefquinome has been considered. Based on this data, the intramuscular injection of cefquinome at a dose of $2 \mathrm{mg} / \mathrm{kg}$ at $24 \mathrm{~h}$ interval is sufficient to maintain serum concentration above $\mathrm{MIC}_{90}$ for most sensitive susceptible pathogens $(0.125 \mu \mathrm{g} / \mathrm{mL})$; these findings indicate the suitability of successful use of cefquinome in sheep and goats. A recommended single daily dose of $2 \mathrm{mg} / \mathrm{kg}$ of cefquinome given intramuscularly achieves therapeutic concentrations in serum exceeding the $\mathrm{MIC}_{90 \text { s }}$ against different susceptible pathogens in sheep and goats. 


\section{Conclusion}

Based on this study, there were no significant differences between the pharmacokinetic parameters of cefquinome (Cobactan 2.5\%) in sheep and goats after repeated intramuscular doses, so that an optimal intramuscular dosage regimen of cefquinome (Cobactan 2.5\%) would be $2 \mathrm{mg} / \mathrm{kg}$ body weight once daily in sheep and goats to achieve and maintain the therapeutic serum levels within a safe limit.

\section{Conflict of Interests}

The authors declare that there is no conflict of interests regarding the publication of this paper.

\section{Acknowledgment}

The authors would like to thank Professor Dr. H. A. El-Banna, Pharmacology Department, Faculty of Veterinary Medicine, Cairo University, Giza, Egypt, for comments on the paper.

\section{References}

[1] D. A. Preston, "Overview of the development of a new class of $\beta$ lactam antibiotics: the carbacephems," Antimicrobic Newsletter, vol. 8, no. 8-9, pp. 58-63, 1992.

[2] S. P. Murphy, M. E. Erwin, and R. N. Jones, "Cefquinome (HR $111 \mathrm{~V}$ ) in vitro evaluation of a Broad-Spectrum cephalosporin indicated for infections in animals," Diagnostic Microbiology and Infectious Disease, vol. 20, no. 1, pp. 49-55, 1994.

[3] V. Guérin-Faublée, G. Carret, and P. Houffschmitt, "In vitro activity of 10 antimicrobial agents against bacteria isolated from cows with clinical mastitis," Veterinary Record, vol. 152, no. 15, pp. 466-471, 2003.

[4] N. Y. Shpigel, D. Levin, M. Winkler, A. Saran, G. Ziv, and A. Bottner, "Efficacy of cefquinome for treatment of cows with mastitis experimentally induced using Escherichia coli," Journal of Dairy Science, vol. 80, no. 2, pp. 318-323, 1997.

[5] D. J. Wilson, R. N. Gonzalez, and H. H. Das, "Bovine mastitis pathogens in New York and Pennsylvania: prevalence and effects of somatic cell count and milk production," Journal of Dairy Research, vol. 80, no. 10, pp. 2592-2598, 1996.

[6] P. Schmid and V. Thomas, "Cefquinome-eight year's antimicrobial susceptibility surveillance in cattle," in Proceedings of the 22nd World Buiatrics Congress, vol. 147, no. 1, pp. 456-464, Hannover, Germany, August 2002.

[7] K. Uney, F. Altan, and M. Elmas, "Development and validation of an HPLC method for the determination of cefquinome in sheep plasma and its application to the pharmacokinetics study," Antimicrobial Agents and Chemotherapy, vol. 55, no. 2, pp. 854859, 2010.

[8] B. Arret, D. P. Johnson, and A. Kirshbaum, "Outline of details for microbiological assays of antibiotics: second revision," Journal of Pharmaceutical Sciences, vol. 60, no. 11, pp. 1689-1694, 1971.

[9] B. N. San Martín, J. Bataglia, P. Hernändez, A. Quiroz, and H. Cañon, "Absorption and excretion of cefquinome in Coho Salmon (Oncorhynchus kisutch) in fresh water at $10^{\circ} \mathrm{C}$," Journal of Veterinary Medicine Series A: Physiology Pathology Clinical Medicine, vol. 45, no. 10, pp. 615-623, 1998.
[10] A. W. Craig and B. Suh, "Protein binding and the antibacterial effects: methods for determination of protein binding," in Antibiotics in Laboratory Medicine, V. Lorian, Ed., pp. 265-297, Williams and Wilkins, Baltimore, Md, USA, 1980.

[11] K. Yamaoka, T. Nakagawa, and T. Uno, "Statistical moments in pharmacokinetics," Journal of Pharmacokinetics and Biopharmaceutics, vol. 6, no. 6, pp. 547-558, 1978.

[12] M. Gibaldi and D. Perrier, Pharmacokinetics, Marcel Dedder, New York, NY, USA, 2nd edition, 1982.

[13] G. W. Snedecor and T. Cochran, Statistical Methods, pp. 502503, Iowa State University Press, Ames, lowa, USA, 6th edition, 1976.

[14] M. A. Tohamy, "Age-related intramuscular pharmacokinetics of cefquinome in sheep," Small Ruminant Research, vol. 99, no. 1, pp. 72-76, 2011.

[15] X. B. Li, W. X. Wu, D. Su, Z. J. Wang, H. Y. Jiang, and J. Z. Shen, "Pharmacokinetics and bioavailability of cefquinome in healthy piglets," Journal of Veterinary Pharmacology and Therapeutics, vol. 31, no. 6, pp. 523-527, 2008.

[16] L. Yuan, J. Sun, R. Wang et al., "Pharmacokinetics and bioavailability of cefquinome in healthy ducks," American Journal of Veterinary Research, vol. 72, no. 1, pp. 122-126, 2011.

[17] V. K. Dumka, V. Dinakaran, B. Ranjan, and S. Rampal, "Comparative pharmacokinetics of cefquinome following intravenous and intramuscular administration in goats," Small Ruminant Research, vol. 113, no. 1, pp. 273-277, 2013.

[18] A. Y. Al-Taher, "Pharinacokinetics of Cefquinome in camels," Journal of Animal and Veterinary Advances, vol. 9, no. 4, pp. 848-852, 2010.

[19] N. S. Haddad, W. M. Pedersoli, and W. R. Ravis, "Pharmacokinetics of gentamicin at steady-state in ponies: serum, urine, and endometrial concentrations," American Journal of Veterinary Research, vol. 46, no. 6, pp. 1268-1271, 1985.

[20] A. M. El-Gendy, M. A. Tohamy, and A. M. Radi, "Pharmacokinetic profile and some pharmacodynamic aspects of cefquinome in chickens," Beni-Suef Veterinary Medical Journal, vol. 19, no. 1, pp. 33-37, 2009.

[21] M. A. Tohamy, M. Ismail, and A. M. El-Gendy, "Comparative pharmacokinetics of cefquinome in ruminant," Journal of the Egyptian Society of Pharmacology and Experimental Therapeutics, vol. 4, no. 1, pp. 12-18, 2006.

[22] A. L. Craigmill, M. A. Pass, and S. Wetzlich, "Comparative pharmacokinetics of amoxicillin administered intravenously to sheep and goats," Journal of Veterinary Pharmacology and Therapeutics, vol. 15, no. 1, pp. 72-77, 1992.

[23] H. A. Elsheikh, A. A. W. Taha, A. I. Khalafallah, and I. A. M. Osman, "Disposition kinetics of enrofloxacin (Baytryl 5\%) in sheep and goats following intravenous and intramuscular injection using a microbiological assay," Research in Veterinary Science, vol. 73, no. 2, pp. 125-129, 2002.

[24] H. A. El-Banna and K. Abo El-Sooud, "Disposition kinetics of ciprofloxacin in lactating goats," Deutsche Tierärztliche Wochenschrift, vol. 105, no. 1, pp. 35-38, 1998.

[25] G. Ziv and F. G. Sulman, "Binding of antibiotics to bovine and ovine serum," Antimicrobial Agents and Chemotherapy, vol. 2, no. 3, pp. 206-213, 1972.

[26] N.-X. Chin, J.-W. Gu, W. Fang, and H. C. Neu, "In vitro activity of cefquinome, a new cephalosporin, compared with other cephalosporin antibiotics," Diagnostic Microbiology and Infectious Disease, vol. 15, no. 4, pp. 331-337, 1992. 
[27] J. A. Orden, J. A. Ruiz-Santa-Quiteria, S. García, D. Cid, and R. de la Fuente, "In vitro activities of cephalosporins and quinolones against Escherichia coli strains isolated from diarrheic dairy calves," Antimicrobial Agents and Chemotherapy, vol. 43, no. 3, pp. 510-513, 1999.

[28] L. Deshpande, M. A. Pfaller, and R. N. Jones, "In vitro activity of ceftiofur tested against clinical isolates of Escherichia coli and Klebsiella pneumoniae including extended spectrum $\beta$ lactamase producing strains," International Journal of Antimicrobial Agents, vol. 15, no. 4, pp. 271-275, 2000.

[29] I. M. Sheldon, M. Bushnell, J. Montgomery, and A. N. Rycroft, "Minimum inhibitory concentrations of some antimicrobial drugs against bacteria causing uterine infections in cattle," Veterinary Record, vol. 155, no. 13, pp. 383-387, 2004.

[30] E. Thomas, V. Thomas, and C. Wilhelm, "Antibacterial activity of cefquinome against equine bacterial pathogens," Veterinary Microbiology, vol. 115, no. 1-3, pp. 140-147, 2006.

[31] J. Wallmann, A. Böttner, L. Goossens et al., "Results of an interlaboratory test on antimicrobial susceptibility testing of bacteria from animals by broth microdilution," International Journal of Antimicrobial Agents, vol. 27, no. 6, pp. 482-490, 2006. 

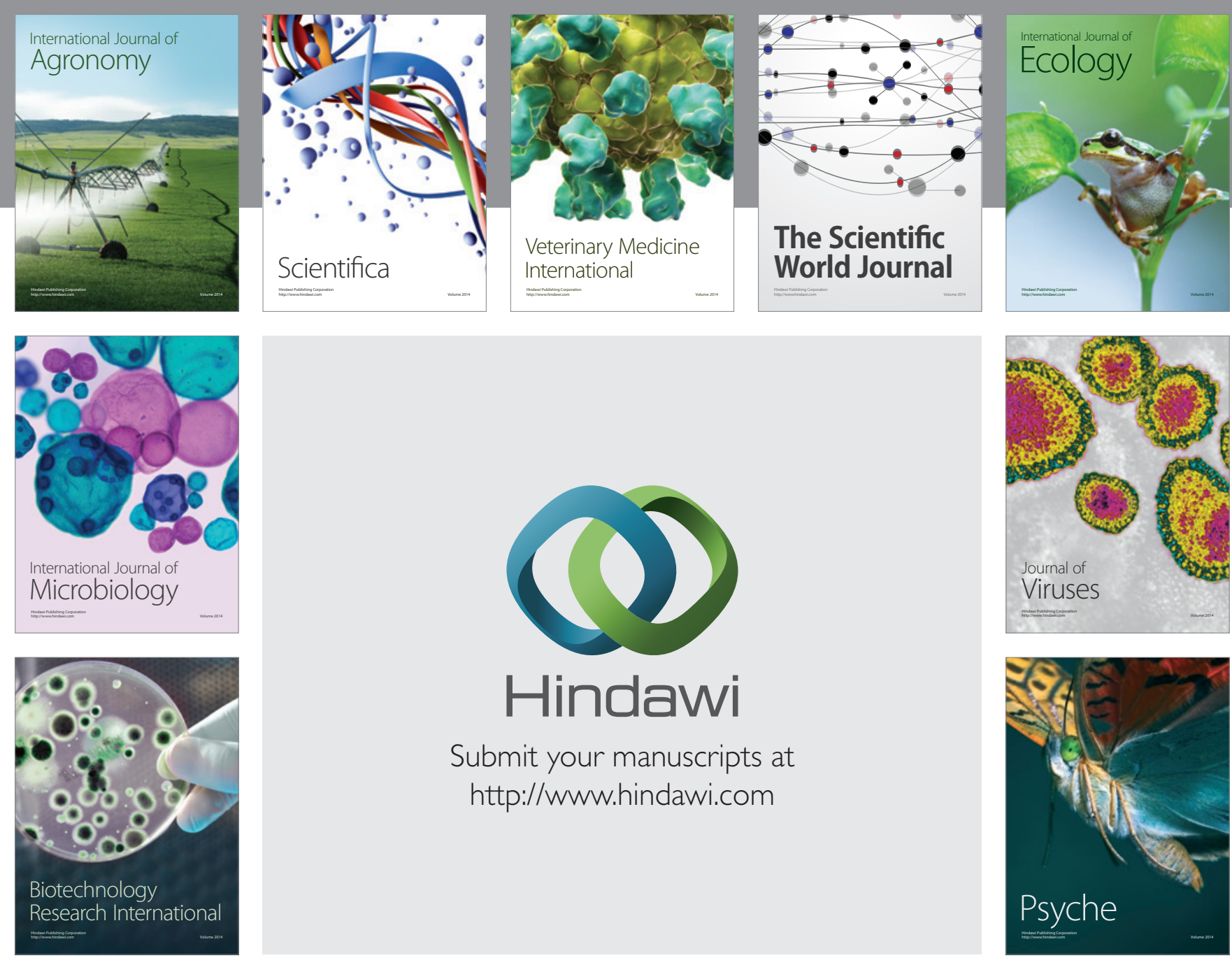

Submit your manuscripts at http://www.hindawi.com
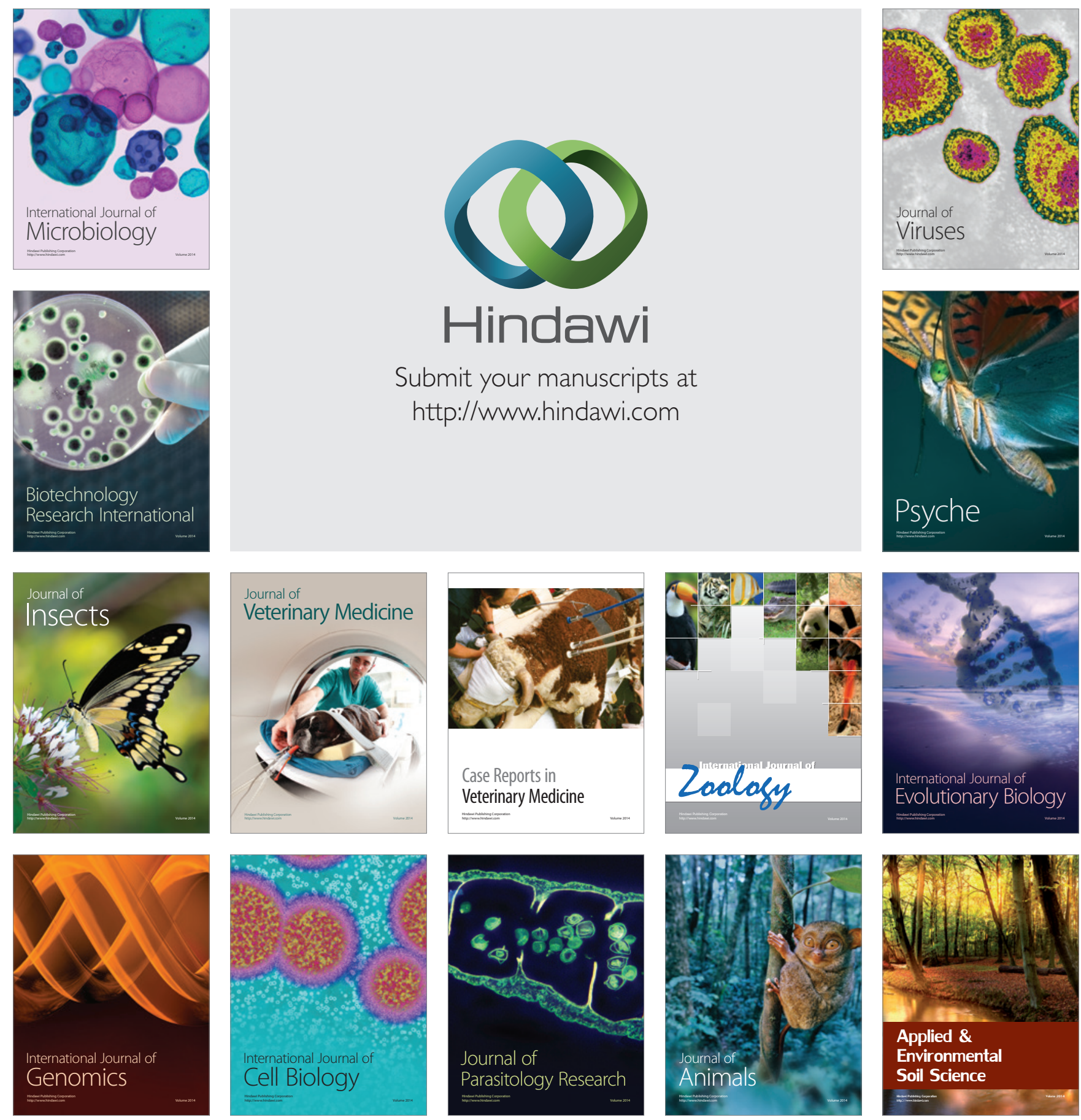